Research Article

\title{
The Impact of China's Low-Carbon Initiative on the Location Expansion of International SPA Enterprises
}

\author{
Zhaoyang Zhao $i$ and Chong Ye \\ School of Economics and Management, Fuzhou University, Fuzhou 350116, China \\ Correspondence should be addressed to Chong Ye; yechong@fzu.edu.cn
}

Received 4 August 2021; Revised 10 October 2021; Accepted 20 October 2021; Published 12 November 2021

Academic Editor: Baogui Xin

Copyright (c) 2021 Zhaoyang Zhao and Chong Ye. This is an open access article distributed under the Creative Commons Attribution License, which permits unrestricted use, distribution, and reproduction in any medium, provided the original work is properly cited.

\begin{abstract}
"Fast fashion" represents a short product life cycle, and international SPA enterprises are therefore criticised as representatives of high energy consumption, pollution, and emissions, which is contrary to China's goal of achieving carbon neutrality. In the context of China's shift to a low-carbon economic development model, how should SPA enterprises breakthrough in the face of China's large-scale market advantage and domestic demand potential? Based on the statistics of 277 prefecture-level cities from 2010 to 2018, this article selects 5 leading international SPA enterprises and uses the difference-in-differences (DID) method to explore the impact of low-carbon initiative on the location expansion of international SPA enterprises. The results suggest that the quantity of location expansions of SPA enterprises in the pilot cities is significantly lower by approximately 0.418 units compared with the nonpilot cities, implying that the low-carbon initiative has a significant inhibitory effect on the location expansion of SPA enterprises. After a series of robustness tests, the conclusion is valid. The results of the heterogeneity test suggest that the suppression effect is mainly found in the subsample of central cities and cities with medium and low levels of economic development. This article proposes that SPA enterprises should reduce their carbon emissions and gradually explore a green and sustainable development path.
\end{abstract}

\section{Introduction}

In recent years, with rapid economic development, industrialisation, and urbanisation, the problem that China needs to solve urgently is the huge amount of carbon dioxide emissions with a large amount of energy consumption (see Figure 1) $[1,2]$. In 2006, China's total carbon emissions reached nearly 6.6 billion tons, marking that China has surpassed the United States as the largest country reporting carbon emissions in the world. In 2020, China's carbon emissions reached 9.899 billion tons, accounting for $30.7 \%$ of global carbon emissions and ranking first in the world. The consistently high carbon emissions have also prompted China to make reducing carbon emissions and developing a low-carbon economy an important strategic goal [3]. To achieve this target, the China Development and Reform Commission (NDRC) officially issued the Notice on Piloting Low-carbon Provinces and Low-carbon Cities (hereinafter referred to as the low-carbon initiative) in 2010, which kicked off the first batch of low-carbon initiative, starting the first batch of pilot work of low-carbon cities, including five provinces, including Guangdong, and eight cities, including Tianjin. However, due to the large area of the first batch of initiative objects, the implementation effect of the initiative policy is not ideal (see Figure 2). Therefore, the NDRC established the second and third batch of initiative lists with cities as the main initiative objects in 2012 and 2017, respectively (Table 1). By 2030, China will have widely formed a green production and green living lifestyle, with carbon emissions reaching a peak and then steadily decreasing, basically achieving its predetermined goal of building a beautiful China. Against this background, a question that needs to be answered urgently is what impact will government environmental regulation have on the development path of traditional high pollution and high energy consumption enterprises?

Low-carbon pilot policies have a significant positive effect on reducing carbon emissions and promoting industrial restructuring [4]. At a time when China is facing serious environmental problems, the priority is to accelerate the 


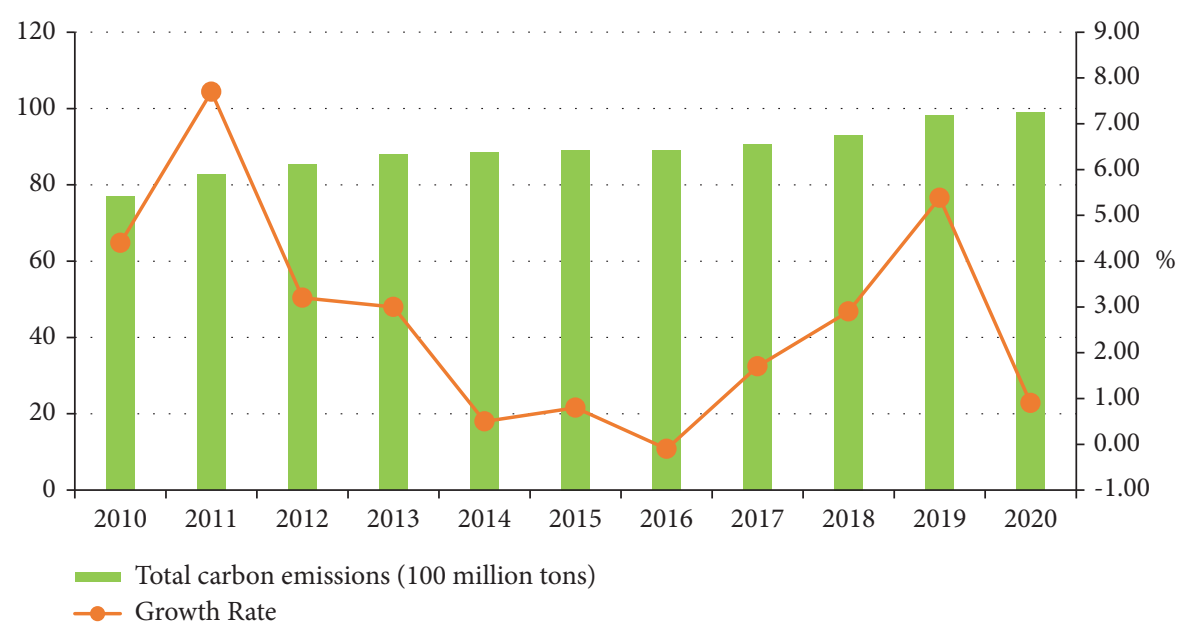

Figure 1: Total Carbon Emissions and Growth Rate in China, 2010-2020.

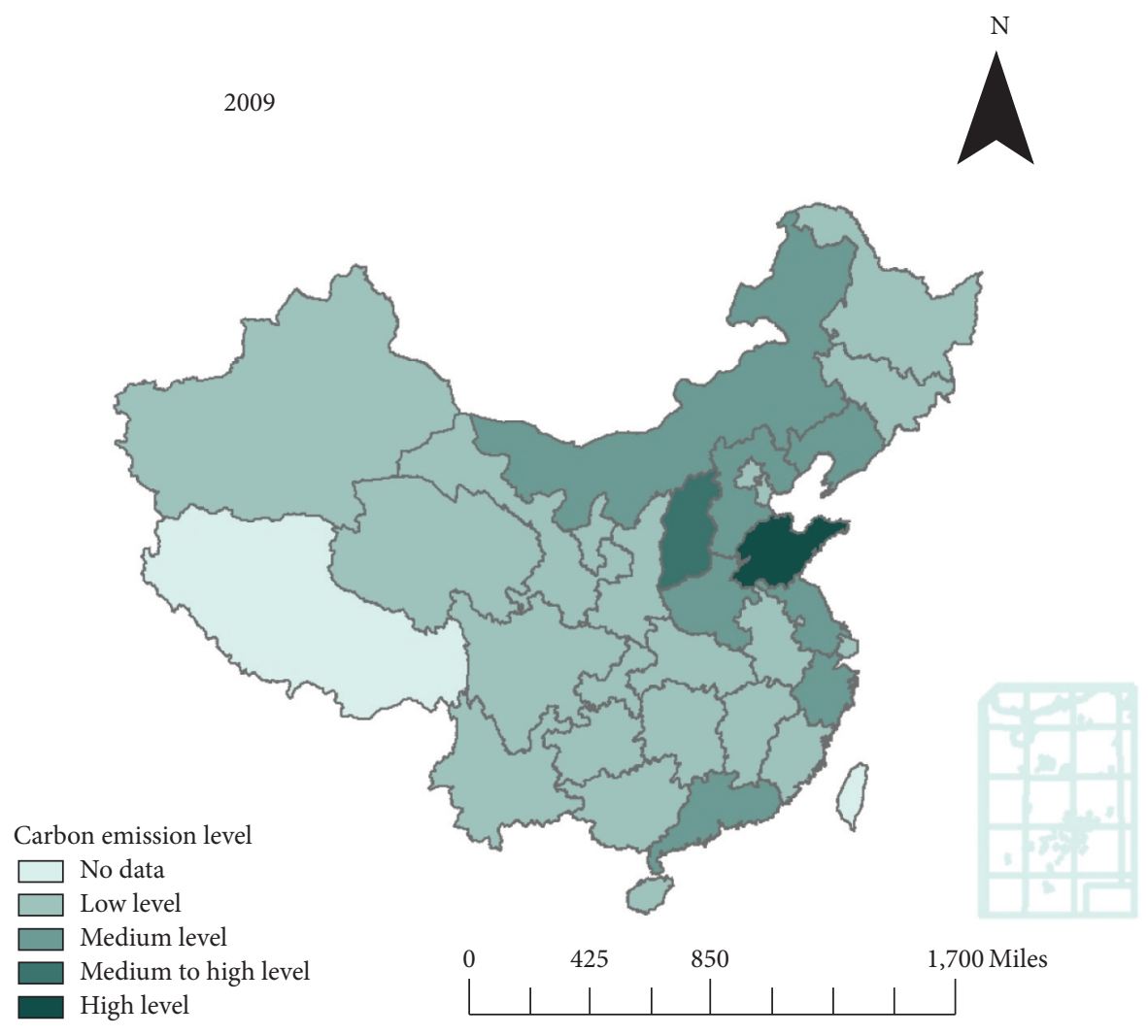

(a)

Figure 2: Continued. 


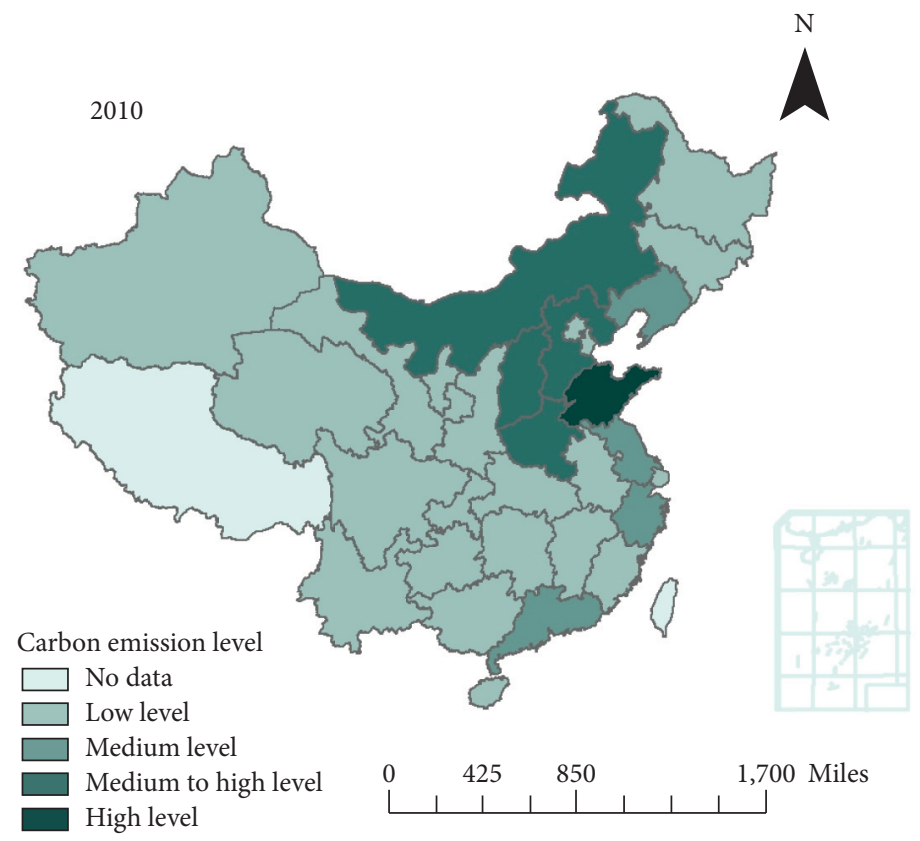

(b)

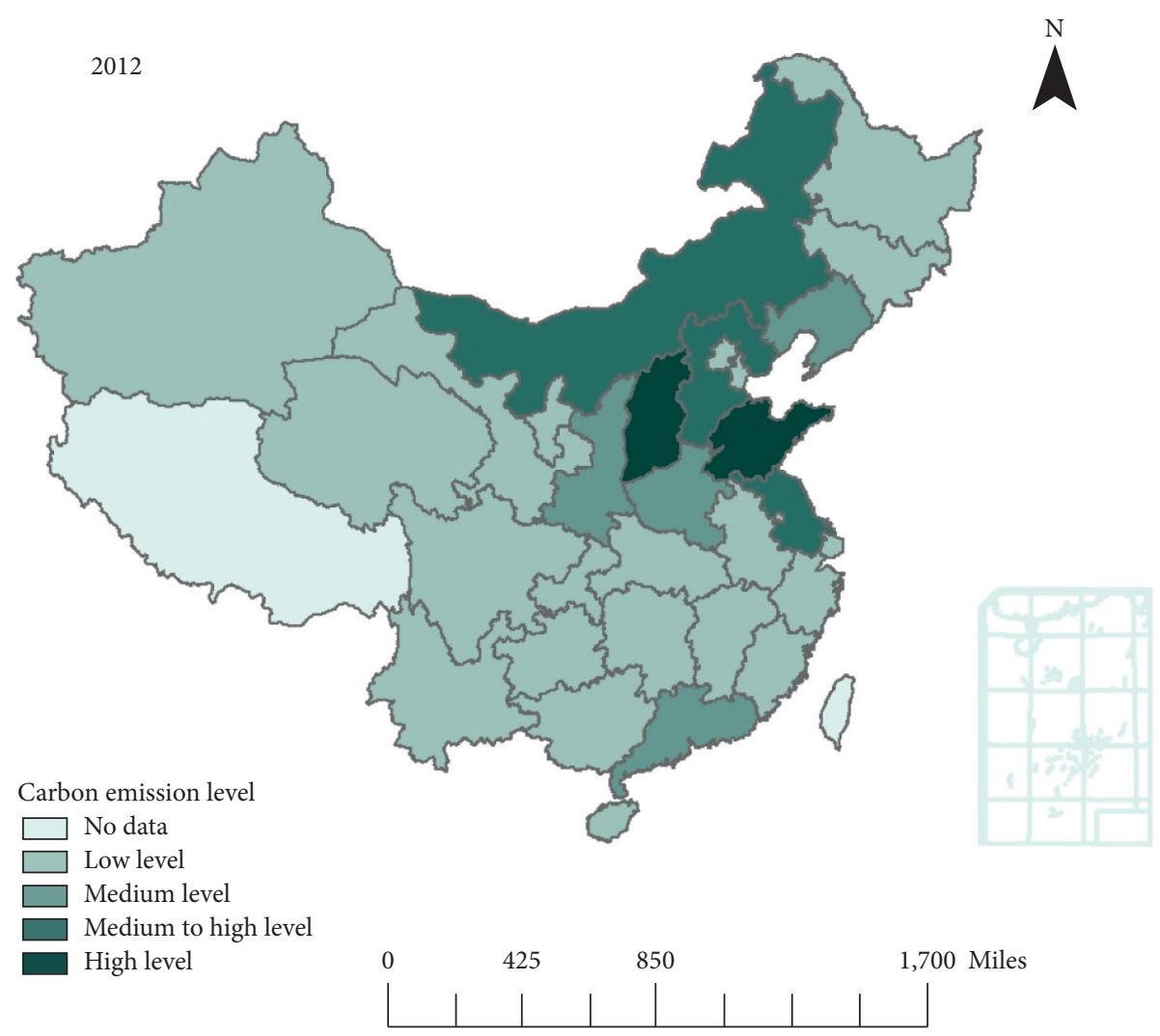

(c)

Figure 2: Continued. 


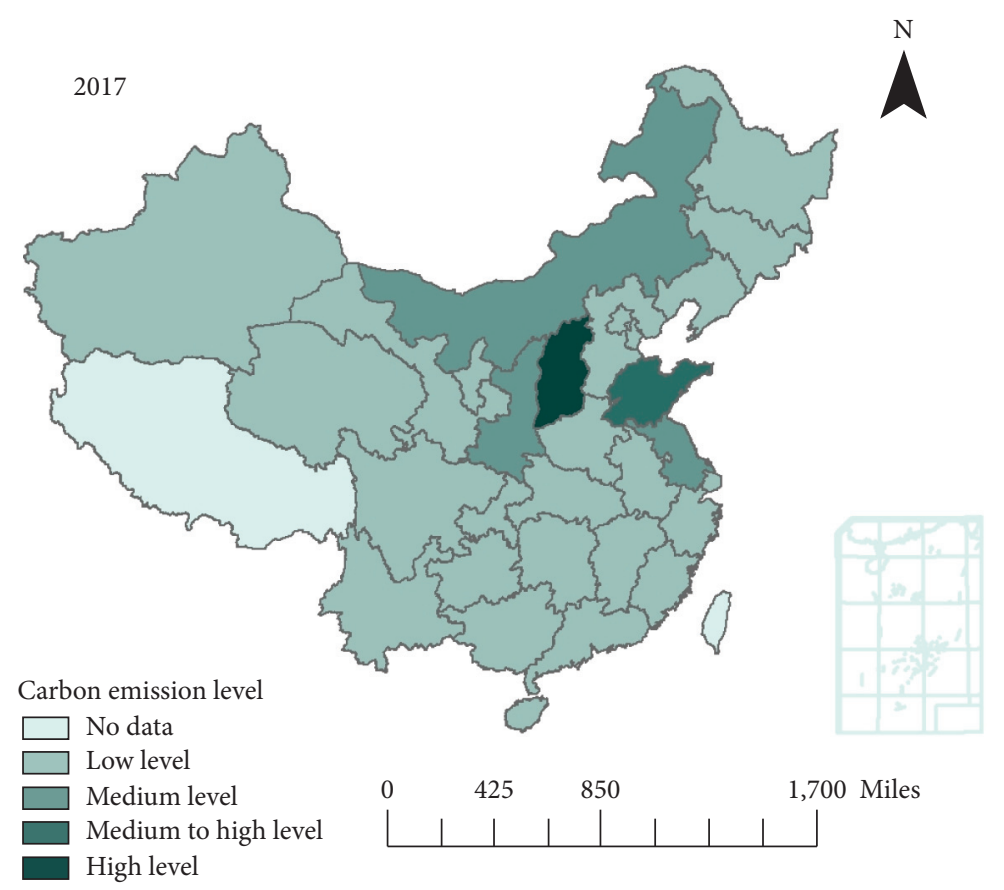

(d)

Figure 2: Evolution of carbon emission intensity in China by province. Figure 2 only contains carbon emission data for each province in mainland China, not including data for Hong Kong, Macau, Taiwan, and the South China Sea under Chinese territory.

TABLE 1: List of three batches of low-carbon pilot cities.

\begin{tabular}{|c|c|c|}
\hline $\begin{array}{l}\text { Pilot } \\
\text { batches }\end{array}$ & Policy Time & List of pilot provinces and cities \\
\hline First batch & July 2010 & $\begin{array}{l}\text { Pilot provinces: Guangdong province, Liaoning province, Hubei province, Shaanxi province, Yunnan province } \\
\text { Pilot cities: Tianjin, Chongqing, Shenzhen, Xiamen, Hangzhou, Nanchang, Guiyang, Baoding }\end{array}$ \\
\hline $\begin{array}{l}\text { Second } \\
\text { batch }\end{array}$ & April 2012 & $\begin{array}{l}\text { Pilot provinces: Hainan province } \\
\text { Pilot cities: Beijing, Shanghai, Shijiazhuang, Qinhuangdao, Jincheng, Hulunbeier, Jilin, Daxinganling, Suzhou, } \\
\text { Huai'an, Zhenjiang, Ningbo, Wenzhou, Chihuahua, Nanping, Jingdezhen, Ganzhou, Qingdao, Jiyuan, Wuhan, } \\
\text { Guangzhou, Guilin, Guangyuan, Zunyi, Kunming, Yan'an, Jinchang, Urumqi }\end{array}$ \\
\hline Third batch & $\begin{array}{c}\text { January } \\
2017\end{array}$ & $\begin{array}{l}\text { Pilot cities: Wuhan, Shenyang, Dalian, Chaoyang, Sunk county, Nanjing, Changzhou, Jiaxing, Jinhua, Quzhou, } \\
\text { Hefei, Huaibei, Huangshan, Liuan, Xuancheng, Sanming, Gongqing, Ji’an, Fuzhou, Jinan, Yantai, Weifang, } \\
\text { Changyang Tujia Group Autonomous County, Changsha, Zhuzhou, Xiangtan, Chenzhou, Zhongshan, liuzhou, } \\
\text { Sanya, Qiongzhong Li and Miao Autonomous County, Chengdu, Yuxi, Pu'er Simao district, Lhasa, Ankang, } \\
\text { Lanzhou, Dunhuang, Xining, Yinchuan, Wuzhong, Changji, Yining, Hotan, Alar, First Division }\end{array}$ \\
\hline
\end{tabular}

The list is disclosed from the official website of China Development and Reform Commission.

linkage mechanism between low-carbon city construction and industrial upgrading [5]. At present, most scholars focus more on the role of low-carbon policy implementation on enterprise technology innovation, but there is little research literature on enterprise expansion strategy. Fang suggested that low-carbon policies have a significant positive impact on technological innovation after studying the relationship between environmental protection policies and manufacturing by developing a structural equation model [6]. Li et al. constructed a DID model to empirically test 121 cities and found that the implementation of low-carbon pilot policies could improve the technological innovation capacity of enterprises [7]. Li and Tao indicate that the promotion of enterprise technological innovation by environmental regulation is more likely to be found in heavily polluting industries [8].
As a key source of carbon emissions and a central organization in the development of low-carbon products, enterprises are important participants in the low-carbon construction [9]. As an apparel retailer in the retail industry that needs to be decarbonized, SPA (Specialty store retailer of Private Label Apparel) enterprises also play a very significant intermediary role in the construction of low-carbon economy and sustainable development practices [6]. In the case of fast fashion companies using the SPA model, the production and sourcing aspects of the supply chain are generally handed over to more specialised third-party apparel enterprises, while the development and planning of their own products is in their controls (see Figure 3) [10]. On one hand, this allows SPA enterprises to quickly gain a competitive advantage in the market, but on the other hand, it also results in SPA enterprises 


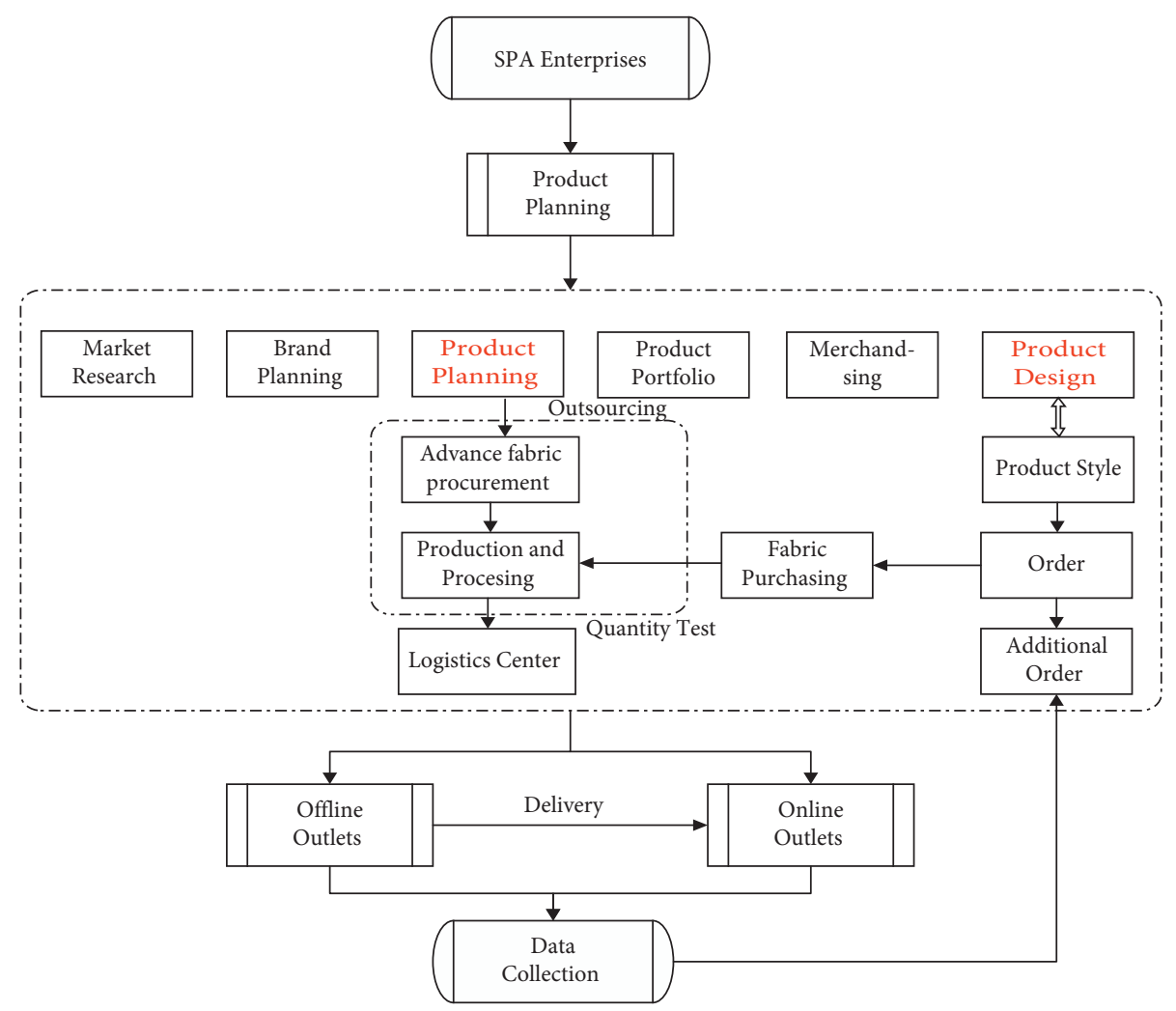

FIgURe 3: SPA mode.

producing goods that have a short life and often have quality problems, which in turn endanger the environment [11]. According to statistics, the production of $0.5 \mathrm{~kg}$ textile will emit $3.5 \mathrm{~kg}$ of carbon dioxide. The carbon emission of clothing manufacturing industry dominated by SPA enterprises accounts for about $10 \%$ of the global carbon emissions every year [12]. In 2018, the global clothing and footwear industry generated 2.1 billion tons of carbon dioxide. In the context of China's increasing emphasis on building a low-carbon economy and implementing low-carbon initiative, SPA enterprises are clearly subject to more demands and challenges [13].

Based on existing research, experts have already conducted studies on the effects of low-carbon policy implementation from different perspectives, providing important theoretical and thinking guidance for this study. However, there has been little research into the impact of low-carbon pilot policies, an important environmental regulation, on the locational expansion of energy-intensive SPA enterprises. Using low-carbon pilot policies as a quasinatural experiment, this study constructs a DID model incorporating macro and supply chain perspectives to explore the impact of low-carbon pilot policies on the locational expansion of international SPA enterprises and conducts a series of heterogeneity analyses and robustness tests based on the quantity of new shop openings of five head international SPA enterprises, namely, UNIQLO, ZARA, GAP, MUJI, and H\&M, from 2011-2019, and statistics from 277 prefecturelevel cities in China from 2010-2018.

In summary, the article's possible contributions lie in the following three areas: (1) After searching web of science for about 105 articles on fast fashion or SPA enterprises, no literature was found that examined the location selection of international SPA enterprises in the Chinese market using the DID method. Therefore, this article is the first to use the DID approach to explore the impact of low-carbon pilot policies on the locational choices of SPA enterprises, extending research in assessing the performance of lowcarbon pilot policies. (2) A study of the location expansion of SPA enterprises based on both macro and supply chain levels, extending the research on location choices affecting retail companies. (3) Based on the conclusion of this article, under the background of strengthening internal and external circulations and focusing on the development of low-carbon economy in China, this article puts forward countermeasures and suggestions on the development mode of SPA and the sustainable development path of international SPA enterprises.

\section{Materials and Methods}

2.1. Difference in Difference Model. This article uses a DID approach to identify the impact of low-carbon city initiative on the locational expansion activities of SPA enterprises in China. The DID method is a measure that analyses the causal relationship between variables and is effective in assessing the effects of policies $[14,15]$. The double difference stems from the city level as well as the year level and compares the difference in location expansion of SPA enterprises in pilot and nonpilot cities before and after the pilot. In terms of research ideas, this article draws on studies in the literature 
such as Wolff and Bell to set up the following econometric model $[16,17]$.

$$
\mathrm{NEW}_{\mathrm{it}}=\boldsymbol{\alpha}+\boldsymbol{\beta T T _ { i t }}+\mathrm{X}_{\mathrm{it}} \gamma+\mathbf{u}_{\mathrm{i}}+\lambda_{\mathrm{t}}+\varepsilon_{\mathrm{it}} .
$$

In model (1), $\mathbf{i}$ and $\mathbf{t}$ denote city and year, respectively; $\mathbf{N E W}_{\text {it }}$ denotes the number of new stores opened by international SPA enterprises; $\mathbf{T T}_{\mathbf{i t}}$ denotes the state in which the low-carbon city pilot is located; $\mathbf{X}_{\mathbf{i t}}$ denotes the control variable; $\mathbf{u}_{\mathbf{i}}$ and $\lambda_{\mathbf{t}}$ denote the city fixed effect and year fixed utility, respectively; $\varepsilon_{i t}$ denotes the random error term. $\beta$ is the DID statistic, which is the core coefficient of most interest in this article, reflecting that the low-carbon city initiative affects the net effect of SPA enterprises' locational expansion activities. If $\beta<0$ and significant, it means that the implementation of lowcarbon city initiative significantly reduces the location expansion behavior of SPA enterprises; if $\beta$ is not significant, it means that low-carbon city initiative has no significant effect on the location expansion activity of SPA enterprises.

\subsection{Variables and Data}

2.2.1. Number of New Shops Opened by International SPA Enterprises. The number of new shops opened by the five international SPA enterprises (UNIQLO, ZARA, GAP, MUJI, and $H \& M$ ), which rank among the top ten in terms of average annual sales in the Chinese market in recent years, is selected as the explained variable in this article. The sample data are collected from the official website of each SPA company.

2.2.2. Low-Carbon Pilot Initiative. If a city has a low-carbon pilot, the value is 1 for that year and subsequent years; otherwise, it is 0 . Based on the policy context above, it is clear that the low-carbon pilot policy contains three batches of pilot cities. The sample in this study starts in 2011 and ends in 2019, so the latter two batches of cities are mainly examined and the first batch of pilot cities are excluded. Following Wang and Qin (2014), it is argued that the impact of low-carbon pilot initiative on the interprovincial level is not significant, and therefore, if a province implements a low-carbon pilot and the cities under its jurisdiction also implement a low-carbon pilot, the implementation will be positioned for the later batch [1]. In addition to this, the timing of the pilot implementation in the second batch of pilot cities is equally controversial as it is close to the end of the year. $\mathrm{Xu}$ and Cui, Wang and $\mathrm{Yu}$ define the implementation time as $2012[18,19]$. Song et al. and Zhang define the implementation time as 2013. Considering the possible lag in policy implementation, the empirical test section of this study defines the implementation time of the second batch of pilot cities as 2013 [20, 21].

Given that multinational retailers usually conduct research six months to a year in advance when setting up a new shop, therefore, all economic indicators used in this article are taken one year ahead and panel data consisting of 277 cities in China from 2010 to 2018 are selected to assess the impact of low-carbon city pilot initiative on the locational expansion activities of SPA enterprises. (At present, there are 294 prefecture-level cities in China, but due to the lack of data in some cities, 277 cities with complete data are selected in this article to ensure the authenticity of the model regression results; see Table 2.)

2.3. Control Variables. The influence of macro factors in the target market is of paramount importance to multinational retailers in their choice of location for expansion. Following Copeland and Taylor, Li and Zou, Auffhammer et al. , Lu et al. , we introduce the following macro control variables [22-25]: (1) PGDP: The level of economic development is measured by the city's gross regional product per capita for the year. (2) FTZ: the degree of openness to the outside world is measured using foreign-invested enterprises above a certain size. (3) XFP: the size of the retail market is measured by the retail sales of consumer goods. (4) CZRZZL: the potential impact of the level of urbanization is measured using the natural growth rate of the municipal area. (5) PERLZB: human capital levels are calculated using the number of students enrolled in general higher education institutions/total regional year-end population.

For retail enterprises, the issue of consumer-facing supply chain collaboration has been a key area of focus within the company [26]. The efficiency of an enterprise's supply chain configuration can significantly affect its internal performance [27]. Compared with the supply chain structure of traditional garment enterprises, high-efficiency supply chain management and perfect logistics network are the keys to support the success of such a system of SPA, so the more flexible the supply chain of SPA enterprises, the more they can respond to today's rapidly changing environment [28]. The ease or difficulty of building a supply chain system in a target location also determines the expansion strategy of an SPA enterprise when selecting a target location for regional expansion. Following Tipu et al. (2018), supply chain flexibility is classified into five dimensions: product, procurement, logistics, new products, and information [29]. This article examines cities along four main dimensions: new products, procurement, logistics, and information, introducing the following supply chain control variables: (1) PEEDUTCH: this article selects the ratio of expenditure on education to expenditure on science and technology as a percentage of local general public budget expenditure to measure regional product R\&D capacity. (2) CAIGOU: using the number of wholesale and retail trade enterprises above a certain size to measure the ease of procurement. (3) PEPOST: measuring logistics efficiency using the number of people employed in transport, storage, and postal services as a proportion of the total city year-end population. (4) The speed of information transmission is measured using the number of people employed in information transmission computer services and software as a proportion of the total city year-end population.

\section{Results and Discussion}

3.1. Parallel Trend Test. Prior to analysis using the DID model, a parallel trend test was required to ensure that there were no significant differences in the location expansion of 
TABLE 2: Predictors of model.

\begin{tabular}{lccc}
\hline Predictor & Abbreviation & Min & Max \\
\hline Number of new stores opened & New & 0 & 30 \\
Low-carbon city pilot & TT & 0 & 1 \\
Level of economic development & PGDP & 8.58 & 12.58 \\
Degree of openness to the outside world & FTZ & 0 & 8.367 \\
Retail market size & XFP & 5.47 & 18.66 \\
Level of urbanization & CZRZZL & -16.77 & 48.57 \\
Human capital & PERLZB & 0.006 & 35.02 \\
Product R\&D capacity & PEEDUTCH & 1.07 & 37.63 \\
Purchasing convenience & CAIGOU & 2.30 & 9.09 \\
Logistics efficiency & PEPOST & 0.006 & 5.83 \\
Speed of information dissemination & PECHUAN & 0.002 & 6.11 \\
\hline
\end{tabular}

SPA enterprises between the pilot and nonpilot cities prior to the implementation of the policy. In this article, we refer to Beck et al. and set up the following model for parallel trend testing [30]:

$$
\begin{aligned}
\text { New }_{i t}= & \alpha+\beta_{1} \text { before }_{4}+\beta_{2} \text { before }_{3}+\beta_{3} \text { before }_{2}+\beta_{4} \text { before }_{1} \\
& +\beta_{5} \text { current }+\beta_{6} \text { after }_{1}+A_{i}+D_{t}+\varepsilon_{i t} .
\end{aligned}
$$

In equation (2), before ${ }_{1}$ to before $_{4}$ denote the dummy variables from 1 to 4 years before the policy implementation, respectively; current denotes the dummy variables in the year of policy implementation; after $_{1}$ denotes the dummy variable for 1 year after the policy implementation. Because low-carbon pilot projects are carried out in three batches and the third batch of pilot cities has the largest number, this article examines the timing of the third batch of low-carbon pilot policies implemented in 2017 as a benchmark. If the coefficients of before ${ }_{1}$ to before ${ }_{4}$ are insignificant in the first four years of the low-carbon pilot policy implementation, and the coefficients of current and after $_{1}$ are significantly negative in the current year and the year after, it indicates a parallel trend between the experimental and control groups. In this article, we plot the coefficient trend in Figure 4 and Table 3 to show the estimation results more visually, with the horizontal axis representing the years before and after implementation and the vertical axis representing the magnitude of the coefficient estimates.

As shown in Figure 4 and Table 3, the coefficients from before $_{1}$ to before ${ }_{4}$ before the implementation of the lowcarbon pilot policy are not significant. It indicates that there is no significant difference in the number of SPA enterprises expanding between the experimental and control groups. The coefficients of current and after $_{1}$ are significantly negative only after the implementation of the low-carbon pilot policy, which proves that the DID model constructed in this article passes the parallel trend test. Low-carbon pilot policies have the most significant policy effects in the year of implementation.

3.2. Total Effect. Table 4 reveals the impact of low-carbon city pilot on the location expansion of SPA enterprises. Among the six models, models (1) to (6) are estimated for all cities, excluding municipalities directly under the central government and planned cities and excluding provincial capitals, respectively. From the consequences, it can be seen that after controlling for city fixed effects as well as year fixed effects, the estimated coefficients of low-carbon city pilot are significantly negative, except for model (6), regardless of whether the control variables are included or not, which indicates that the low-carbon city pilot policy in general significantly and negatively affects the locational expansion behavior of international SPA enterprises in the Chinese market. The economic significance of the pilot coefficient for low-carbon cities is explored in model (2). Other things being equal, the quantity of new shops opened by SPA enterprises in low-carbon pilot cities is reduced by 0.418 units on average compared with nonpilot cities.

For the results of control variables in the model, we still use model (2) to interpret. The estimated coefficient of economic development level is significantly positive, indicating that the improvement of economic development level will significantly increase the location expansion behavior of international SPA enterprises, which is consistent with the research conclusion of Yang [31]. The estimated coefficient of human capital is significantly positive, indicating that international SPA enterprises tend to go to the region to accelerate the location expansion with the improvement in regional human capital level, which is consistent with the conclusion of $\mathrm{Fu}$ and $\mathrm{Wu}$ [32]. The estimated coefficient of information propagation speed is significantly negative, and this may be due to the fact that in the regions where the information dissemination speed is fast, retail enterprises need to face the problems of order quantity decision making, price fluctuation, inventory responsibility imbalance, and other related problems in the supply chain and need to frequently deal with the increasing demand variation caused by the game between the external environment and other aspects. As a result, clothing retail enterprises in the information flow through the fast region to intensify competition. The estimated coefficient of logistics efficiency is significantly positive, which indicates that international SPA enterprises will increase the quantity of location expansion in developed logistics areas, which is the same as the research conclusion of Li et al. [33].

3.3. Heterogeneity Analysis. Different cities have certain differences in economic structure, policy implementation, and market size, and these differences may lead to different 


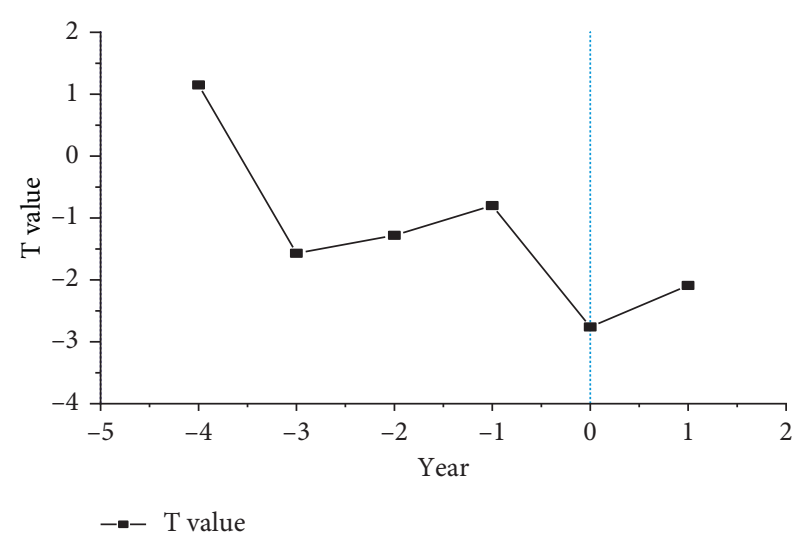

Figure 4: Parallel trend test. Horizontal axis representing the years before and after implementation and the vertical axis representing the magnitude of the coefficient estimates.

TABLe 3: Parallel trend test regression results.

\begin{tabular}{|c|c|}
\hline TT & (1) \\
\hline Before 4 & $\begin{array}{l}0.258 \\
(1.15)\end{array}$ \\
\hline Before 3 & $\begin{array}{l}-0.373 \\
(-1.57) \\
\end{array}$ \\
\hline Before2 & $\begin{array}{l}-0.482 \\
(-1.28)\end{array}$ \\
\hline Before1 & $\begin{array}{l}-0.227 \\
(-0.80)\end{array}$ \\
\hline Current & $\begin{array}{c}-0.929^{* *} \\
(-2.76)\end{array}$ \\
\hline Affter 1 & $\begin{array}{c}-0.507^{*} \\
(-2.09)\end{array}$ \\
\hline Cons_ & $\begin{array}{c}0.334^{* * *} \\
(6.24)\end{array}$ \\
\hline Urban fixed & $\mathrm{Y}$ \\
\hline Year fixed & $\mathrm{Y}$ \\
\hline$R^{2}$ & 0.038 \\
\hline
\end{tabular}

effects of low-carbon pilot policies on different cities, which in turn affect the locational expansion behavior of SPA enterprises. In view of this, this work further examines the regional differences in the impact of low-carbon pilot policies on the locational expansion of SPA enterprises, following two different lines of enquiry, following the approach of Zhang [21]: (1) The sample cities were divided into three subsamples according to geographical location: eastern, central, and western. (2) The cities were divided into three equal parts based on the 2019 per capita gross regional product.

As shown in Table 5, the inhibitory effect of low-carbon city pilot on the location expansion of SPA enterprises is more significant in the subsamples of central cities, cities with low and medium economic development levels. The reason for the finding may lie in the fact that cities with more developed economies tend to have larger energy consumption, leading to higher levels of carbon emissions, carbon lock-in, and carbon dependence. The effect of lowcarbon pilot policy implementation shows an overall decreasing trend with rising city size. In contrast, medium and smaller cities in the middle of the country have lower carbon emission levels and are more responsive to lowcarbon pilot initiative, so they can quickly exert the inhibiting effect of low-carbon pilot initiative on the location expansion of SPA enterprises, and the initiatives are more effective.

3.4. Robustness Tests. This article follows Cheng et al. and Liang in conducting robustness tests to verify the reliability of the regression results $[34,35]$.

3.4.1. Preceding the Year of Policy Implementation for the Second Batch of Low-Carbon Pilot Cities. To ensure that the randomness of low-carbon pilot initiative enactment is not disturbed by other policies, a counterfactual test is conducted by varying the timing of low-carbon pilot policy implementation. In this article, the regressions were conducted after the year of implementing low-carbon pilot initiative in 2013 for each city was uniformly advanced by one year, and the results are shown in model (1) in Table 6. From the regression results, it can be found that the estimated coefficients of low-carbon pilot policies are not significant, indicating that the previous estimation results have good robustness.

3.4.2. The Interference of Extreme Values Was Excluded. The variables in this work are very different from each other, and there are extreme outliers. Therefore, this work uses the "shrinkage method," where the highest and lowest $2 \%$ of all control variables are shrunk, and the shrunken samples are regressed again. The results are shown in model (2) in Table 6, where the low-carbon city pilot coefficient is significantly negative at the $1 \%$ level, indicating that the low-carbon pilot policy significantly reduces the locational expansion behaviour of SPA enterprises, supporting the previous findings.

3.4.3. Excluding the Interference of China's Carbon Emissions Trading System Pilot Policy (ETS). During the sample time of this article, the location expansion behavior of SPA enterprises may also be influenced by other policies in the same time period, such as China's carbon emission trading pilot policy that started in 2011. To test whether the implementation of this policy interferes with the impact of the low-carbon pilot policy on the locational expansion behavior of SPA enterprises in China, a dummy variable for the carbon emissions trading system pilot policy is further included in the model and regressed. It can be seen that the coefficient values for the low-carbon pilot policy remain significantly negative, which indicates that the implementation of ETS does not interfere with the policy effects of the low-carbon pilot policy.

3.5. Placebo Test. In this article's natural experiment, there may be differences in city characteristics other than whether they are low-carbon pilot cities between the treatment and 
TABLE 4: Baseline regression results.

\begin{tabular}{|c|c|c|c|c|c|c|}
\hline Variables & $(1)$ & $(2)$ & (3) & $(4)$ & $(5)$ & $(6)$ \\
\hline$T T$ & $\begin{array}{c}-0.422^{* * *} \\
(-3.81)\end{array}$ & $\begin{array}{c}-0.418^{* *} \\
(-3.07)\end{array}$ & $\begin{array}{c}-0.232^{* *} \\
(-2.70)\end{array}$ & $\begin{array}{c}-0.338^{* *} \\
(-3.21)\end{array}$ & $\begin{array}{c}-0.334^{* *} \\
(-2.99)\end{array}$ & $\begin{array}{l}-0.20 \\
(-1.50)\end{array}$ \\
\hline$P G D P$ & & $\begin{array}{l}0.516^{*} \\
(2.07) \\
\end{array}$ & & $\begin{array}{c}0.643^{* * *} \\
(3.41)\end{array}$ & & $\begin{array}{c}0.477^{*} \\
(2.13)\end{array}$ \\
\hline FTZ & & $\begin{array}{c}-0.17 \\
(-1.43) \\
\end{array}$ & & $\begin{array}{c}-0.17 \\
(-1.87) \\
\end{array}$ & & $\begin{array}{c}0.08 \\
(-0.74)\end{array}$ \\
\hline$X F P$ & & $\begin{array}{c}0.11 \\
(0.51) \\
\end{array}$ & & $\begin{array}{c}0.04 \\
(0.22) \\
\end{array}$ & & $\begin{array}{c}0.03 \\
(0.16)\end{array}$ \\
\hline$C Z R Z Z L$ & & $\begin{array}{c}0.01 \\
(1.45) \\
\end{array}$ & & $\begin{array}{c}0.01 \\
(0.99) \\
\end{array}$ & & $\begin{array}{c}0.01 \\
(1.16) \\
\end{array}$ \\
\hline PERLZB & & $\begin{array}{l}0.087^{*} \\
(2.04) \\
\end{array}$ & & $\begin{array}{l}0.071^{*} \\
(2.20)\end{array}$ & & $\begin{array}{l}0.131^{*} \\
(2.17) \\
\end{array}$ \\
\hline PEEDUTCH & & $\begin{array}{c}0.70 \\
(0.73) \\
\end{array}$ & & $\begin{array}{c}0.21 \\
(0.29) \\
\end{array}$ & & $\begin{array}{c}0.63 \\
(0.73) \\
\end{array}$ \\
\hline CAIGOU & & $\begin{array}{c}0.04 \\
(0.36) \\
\end{array}$ & & $\begin{array}{c}-0.05 \\
(-0.61) \\
\end{array}$ & & $\begin{array}{l}-0.001 \\
(-0.01) \\
\end{array}$ \\
\hline PECHUAN & & $\begin{array}{c}-0.018^{* * *} \\
(-9.52)\end{array}$ & & $\begin{array}{c}-0.005^{* * *} \\
(-3.30)\end{array}$ & & $\begin{array}{c}-0.032^{* * *} \\
(-13.74)\end{array}$ \\
\hline PEPOST & & $\begin{array}{c}0.004^{* * *} \\
(3.73) \\
\end{array}$ & & $\begin{array}{l}0.002^{*} \\
(2.51) \\
\end{array}$ & & $\begin{array}{c}0.005^{* * *} \\
(3.53)\end{array}$ \\
\hline cons_ & $\begin{array}{c}0.334^{* * *} \\
(5.22)\end{array}$ & $\begin{array}{c}-6.50 \\
(-1.79) \\
\end{array}$ & $\begin{array}{c}0.260^{* * *} \\
(5.36)\end{array}$ & $\begin{array}{c}-6.212^{*} \\
(-2.28) \\
\end{array}$ & $\begin{array}{c}0.180^{* *} \\
(3.04)\end{array}$ & $\begin{array}{c}-4.95 \\
(-1.55) \\
\end{array}$ \\
\hline Urban fixed & $\mathrm{Y}$ & $\mathrm{Y}$ & $\mathrm{Y}$ & $\mathrm{Y}$ & $\mathrm{Y}$ & $\mathrm{Y}$ \\
\hline Year fixed & $\mathrm{Y}$ & $\mathrm{Y}$ & $\mathrm{Y}$ & $\mathrm{Y}$ & $\mathrm{Y}$ & $\mathrm{Y}$ \\
\hline$N$ & 2493 & 2493 & 2412 & 2412 & 2205 & 2205 \\
\hline$R^{2}$ & 0.024 & 0.088 & 0.023 & 0.051 & 0.015 & 0.130 \\
\hline
\end{tabular}

${ }^{*},{ }^{* *}$, and ${ }^{* * *}$ denote $10 \%, 5 \%$ and $1 \%$ significance levels, respectively.

TABLE 5: Heterogeneity.

\begin{tabular}{|c|c|c|c|c|c|c|}
\hline \multirow{2}{*}{ Variables } & \multicolumn{3}{|c|}{ Different geographical locations } & \multicolumn{3}{|c|}{ Different levels of economic development } \\
\hline & East & Middle & West & Low & Medium & High \\
\hline TT & $\begin{array}{l}-0.499 \\
(-1.82)\end{array}$ & $\begin{array}{c}-0.556^{* * *} \\
(-3.39)\end{array}$ & $\begin{array}{l}-0.039 \\
(-0.25)\end{array}$ & $\begin{array}{c}-0.168^{*} \\
(-1.98)\end{array}$ & $\begin{array}{c}-0.377^{* *} \\
(-3.08)\end{array}$ & $\begin{array}{l}-0.394 \\
(-1.37)\end{array}$ \\
\hline Control variables & $\mathrm{Y}$ & $\mathrm{Y}$ & $\mathrm{Y}$ & $\mathrm{Y}$ & $\mathrm{Y}$ & $\mathrm{Y}$ \\
\hline Urban fixed & $\mathrm{Y}$ & Y & $\mathrm{Y}$ & $\mathrm{Y}$ & Y & $\mathrm{Y}$ \\
\hline Year fixed & $\mathrm{Y}$ & Y & Y & Y & Y & Y \\
\hline$R^{2}$ & 0.119 & 0.105 & 0.106 & 0.087 & 0.081 & 0.132 \\
\hline
\end{tabular}

${ }^{*},{ }^{* *}$, and ${ }^{* * *}$ denote $10 \%, 5 \%$ and $1 \%$ significance levels, respectively.

control groups before the low-carbon pilot initiative is introduced. Therefore, this article refers to Liu et al. (2015) and takes the following approach to indirectly test whether these omitted features may have an impact on the estimation results [36]. First, we derive an expression for the coefficient estimate of $\mathrm{New}_{\mathbf{i t}}, \boldsymbol{\beta}_{\mathbf{r}}$, based on equation (1).

$$
\beta+\delta * \frac{\operatorname{cov}\left(t t_{i t}, \varepsilon_{i t} \mid \tau\right)}{\operatorname{var}\left(t t_{i t}, \tau\right)},
$$

where $\tau$ denotes all control variables. If any variable can be found to replace $\mathbf{t t}$, and this variable does not theoretically affect the corresponding $\mathbf{N e w}_{\mathbf{i t}}(\beta=0)$, then estimating $\beta_{\mathbf{r}}=0$, we can prove that $\delta=0$; the unobserved factors do not affect the estimation results. To this end, this work regresses the lowcarbon pilot initiative shocks to cities after they become random (generated by stata16) and repeats this random regression process 1000 times so that $\mathbf{N e w}_{\mathbf{i t}}$ is not affected $\left(\beta_{\mathbf{r}}^{\text {ran } \mathbf{d o ~} \mathbf{m}}=0\right)$. In this work, we show the estimated distribution of the $\beta_{\mathbf{r}}^{\text {ran do } \mathrm{m}}$ according to a thousand times in Figure 5 and find that for 1000 random processes, $\beta_{r}^{\text {ran }} \mathbf{d o} \mathbf{m}$ is indeed all distributed around 0 and is essentially normally distributed. Therefore, it can be inferred that $\delta=0$, it is proved that the unobserved urban characteristics hardly affect the estimation results, and the previous estimation results are robust. 
TABLE 6: Robustness tests results.

\begin{tabular}{lccc}
\hline Variables & $(1)$ & $(2)$ & $(3)$ \\
\hline TT & 0.047 & $-0.521^{* * *}$ & $(-3.78)$ \\
& $(0.32)$ & & $(-2.32)$ \\
ETS & & -0.232 \\
Control variables & $\mathrm{Y}$ & $\mathrm{Y}$ & $-(1.62)$ \\
Urban fixed effects & $\mathrm{Y}$ & $\mathrm{Y}$ \\
Year fixed effects & $\mathrm{Y}$ & $\mathrm{Y}$ & $\mathrm{Y}$ \\
$N$ & 2493 & $\mathrm{Y}$ & 2493 \\
$R^{2}$ & 0.083 & 2493 & 0.082 \\
${ }^{*},{ }^{* *}$, and ${ }^{* * *}$ denote $10 \%, 5 \%$ and $1 \%$ significance levels, respectively. & & 0.054 \\
\end{tabular}

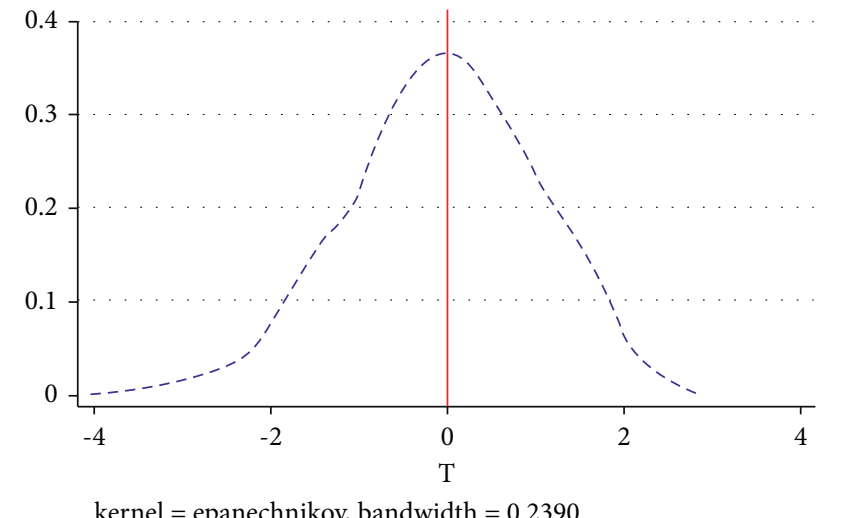

Figure 5: Placebo test.

\section{Conclusions}

Based on statistics from 277 prefecture-level cities from 2010 to 2018 , this study investigates the impact of low-carbon pilot initiative on the locational expansion of SPA enterprises using a DID model as a quasinatural experiment. The results show that (1) the implementation of low-carbon initiative policy significantly inhibits the location expansion behavior of international spa enterprises in pilot cities; (2) the inhibition effect of low-carbon initiative on the location expansion of international SPA enterprises in central cities is higher than that in eastern and western cities; and (3) the inhibition effect of location expansion in middle and low economic development level cities is significantly higher than that in high economic development level cities. For the fast fashion enterprises using SPA mode, they produce a lot of carbon emissions in the production, sales, transportation, and other links. In the areas with strict environmental regulations, it is obviously not conducive to the sustainable development and healthy competition of SPA enterprises. Therefore, the international SPA enterprises should be committed to reducing the total carbon emissions of the whole industrial chain in the development of China's market and focus on the production and transportation links, so as to find a road suitable for sustainable development by choosing suitable low-carbon fabrics and planning green path. Meanwhile, international SPA enterprises can choose to adopt centralized competition strategy and differentiated competition strategy to expand to central China and medium- and low-sized cities with differentiated products such as green low-carbon clothing and establish green brand image to Chinese consumers in the process of expansion.

\section{Data Availability}

The processed data required to reproduce these findings cannot be shared at this time as the data also form part of an ongoing study.

\section{Conflicts of Interest}

The authors declare no conflicts of interest.

\section{Authors' Contributions}

Zhaoyang Zhao developed the methodology, performed data curation, reviewed and edited the article. Chong Ye conceptualized the study, developed the methodology, performed data curation, wrote the original draft, reviewed and edited the article, and performed validation.

\section{Acknowledgments}

This research was funded by the National Social Science Foundation of China, grant number 19FJYB043.

\section{References}

[1] G. Y. An, "Analysis of the influence of low-carbon economy on China's textile and clothing export," Light and Textile Industry and Technology, vol. 50, 2020.

[2] M. Auffhammer, W. Sun, and J. Wu, "The decomposition and dynamics of industrial carbon dioxide emissions for 287 Chinese cities in 1998-2009," Journal of Economic Surveys, vol. 30, 2016.

[3] T. Beck, R. Levine, and A. Levkov, "Big bad banks? The winners and losers from bank deregulation in the United States," The Journal of Finance, vol. 65, no. 5, pp. 1637-1667, 2010.

[4] D. R. Bell, S. Gallino, and A. Moreno, "Inventory showrooms and customer migration in omni-channel retail: the effect of product information," SSRN Electronic Journal, 2013.

[5] K. W. Brown and T. Kasser, "Are psychological and ecological well-being compatible? The role of values, mindfulness, and lifestyle," Social Indicators Research, vol. 74, no. 2, pp. 349-368, 2005. 
[6] Q. Fang, "The impact of environmental policy on low-carbon technology innovation performance of Chinese manufacturing industry," in Proceedings of the International Conference on Humanities and Social Science Research, Paris, France, Atlantis Press, 2015.

[7] L. H. Li, J. Wang, and Y. F. Xu, "The influence of initiative of low-carbon city on enterprise technology innovation: an empirical research based on difference-in-different mode," Ecological Economy, vol. 35, pp. 48-54, 2019.

[8] L. Li and F. Tao, "Selection of optimal environmental regulation intensity for Chinese manufacturing industry-based on the green TFP perspective," China Industrial Economics, vol. 5, pp. 70-82, 2012.

[9] K. A. Durgesh, "Demand chain management: factors enhancing market responsiveness capabilities," Journal of Marketing Channels, vol. 19, pp. 101-119, 2012.

[10] X. X. Fu and L. X. Wu, "Technical efficiency, capital deepening and regional differences: an analysis based on stochastic frontier of the convergence of China," Economic Research Journal, vol. 10, pp. 52-61, 2006.

[11] M. Gehrsitz, "The effect of low emission zones on air pollution and infant health," Journal of Environmental Economics and Management, vol. 83, pp. 121-144, 2017.

[12] M. K. Hingley, "Power imbalanced relationships: cases from UK fresh food supply," International Journal of Retail \& Distribution Management, vol. 33, no. 8, pp. 551-569, 2005.

[13] M. Laura, M. Antonella, and C. Federico, "Production and supply network strategies within the fashion industry," International Journal of Production Economics, vol. 163, pp. 173-188, 2015.

[14] H. Li and Q. Zou, "Environmental regulations, resource endowments and urban industry transformation:comparative analysis of resource-based and non-resource-based cities," Economic Research, vol. 17, pp. 182-198, 2018.

[15] E. Bardaka, M. S. Delgado, and R. Florax, "A spatial multiple treatment/multiple outcome difference-in-differences model with an application to urban rail infrastructure and gentrification," Transportation Research Part A: Policy and Practice, vol. 121, pp. 325-345, 2019.

[16] H. Wolff, "Keep your clunker in the suburb: low-emission zones and adoption of green vehicles," Economic Journal, vol. 124, no. 578, pp. F481-F512, 2014.

[17] D. R. Bell, S. Gallino, and A. Moreno, "Offline showrooms in omni-channel retail: demand and operational benefits," Management Science, vol. 64, no. 4, pp. 1629-1651, 2017.

[18] J. X. and J. B. Cui, "Low carbon city and enterprise green technology innovation," China Industrial Economics, vol. 12, pp. 178-196, 2020.

[19] Q. Wang and S. Yu, "Assessment of green growth effects of low carbon pilot policies in China from the perspective of urban heterogeneity," Soft Science, vol. 34, no. 9, pp. 1-8, 2020.

[20] Q. Liu and Y. Lu, "Firm investment and exporting: evidence from China's value-added tax reform," Journal of International Economics, vol. 97, no. 2, pp. 392-403, 2015.

[21] Z. Liu, J. Wang, and C. W. Thomas, "What motivates local sustainability policy action in China? The case of low-carbon city pilot program," Urban Affairs Review, vol. 24, no. 1, 2021.

[22] J. J. Lu and N. Wang, "Big data capabilities, supply chain flexibility and retailer performance," Journal of Commercial Economics, vol. 24, pp. 103-106, 2020.

[23] W. Ma, M. de Jong, M. de Bruijne, and R. Mu, "Mix and match: configuring different types of policy instruments to develop successful low carbon cities in China," Journal of Cleaner Production, vol. 282, no. 2-3, Article ID 125399, 2021.
[24] L. P. Nie, "The application of SPA model in apparel enterprises under the new retail environment," Logistics \& Material Handling, vol. 23, pp. 147-149, 2018.

[25] H. Song, Y. J. Sun, and D. K. Chen, “Assessment for the effect of government air pollution control policy: empirical evidence from "low-carbon city" construction in China," Management World, vol. 9, pp. 1-8, 2019.

[26] S. A. A. Tipu and K. Fantazy, "Exploring the relationships of strategic entrepreneurship and social capital to sustainable supply chain management and organizational performance," International Journal of Productivity and Performance Management, vol. 67, no. 9, pp. 2046-2070, 2018.

[27] G. H. Wang and Y. H. Qin, "Carbon footprint space-time pattern analysis from pilot low-carbon provinces in China," Journal of Guilin University of Technology, vol. 34, pp. 371375, 2014.

[28] D. Wang and S. Yu, "Local practices, problems and thoughts from governance perspective on affiliation of regional prestigious schools," Open Journal of Leadership, vol. 9, no. 1, pp. 1-10, 2020.

[29] Y. Q. Wang, "How to realize sustainable development of fast fashion industry," Low-carbon World, vol. 9, pp. 278-279, 2018.

[30] H. Wolff, "Keep your clunker in the suburb: low-emission zones and adoption of green vehicles," The Economic Journal, vol. 124, no. 578, pp. F481-F512, 2014.

[31] G. Q. Xiong, D. Q. Shi, and M. N. Li, "The effect of low-carbon pilot cities on the green technology innovation of enterprises," Science Research Management, vol. 41, pp. 93-102, 2020.

[32] G. Q. Xu, Z. Y. Liu, and Z. H. Jiang, "Decomposition model and empirical study of carbon emissions for china, 19952004," China Population, Resources and Environment, vol. 16, pp. 158-161, 2016.

[33] J. $\mathrm{Xu}$ and J. B. Cui, "Low-carbon cities and firms' green technological innovation," China Industrial Economics, vol. 12, p. 178, 2020.

[34] L. Yang, “An empirical study of foreign retailers' location choice behavior in the yangtze river delta," Business Times, vol. 29, pp. 23-24, 2010.

[35] H. Zhang, "Can low-carbon city construction reduce carbon emissions? Evidence from a quasi-natural experiment business," Management Journal, vol. 6, pp. 25-41, 2020.

[36] F. Zheng and B. Y. Tang, "Supply chain optimization analysis of garment enterprises based on Internet + ," Wool Textile Journal, vol. 47, pp. 55-59, 2019. 